\title{
Who Cares If You Vote? Partisan Pressure and Social Norms of Voting
}

\author{
Edward Fieldhouse $^{1}$ (D) $\cdot$ David Cutts $^{2} \cdot$ Jack Bailey $^{1}$
}

Accepted: 11 November 2020 / Published online: 3 December 2020

(c) The Author(s) 2020

\begin{abstract}
Social norms are important in explaining why people vote, but where do those norms come from and is social pressure motivated by partisanship? In this article, we use political discussion network data to examine the role of party identification in shaping the relationship between injunctive norms, civic duty and voter turnout. More specifically, we examine the extent to which both the application of injunctive norms and their impact on turnout is affected by shared partisan identification. We find that citizens are more likely to perceive normative pressure to vote from fellow partisans, a phenomenon we refer to as "partisan pressure". However we do not find consistent evidence for the hypothesis that turnout is more closely related to the approval or disapproval of discussants who share a partisanship. By separating the role of social pressure from that of normative beliefs we also demonstrate that injunctive norms affect voter turnout both directly and indirectly by increasing civic duty.
\end{abstract}

Keywords Social norms $\cdot$ Voting $\cdot$ Turnout $\cdot$ Partisanship $\cdot$ Political discussion networks $\cdot$ Social influence $\cdot$ Civic duty

Electronic supplementary material The online version of this article (https://doi.org/10.1007/s1110 9-020-09661-y) contains supplementary material, which is available to authorized users.

Edward Fieldhouse

Ed.fieldhouse@manchester.ac.uk

1 School of Social Sciences, University of Manchester, Humanities Bridgeford Street, Manchester M13 9PL, UK

2 School of Government and Society, University of Birmingham, Room 3E15 (East Wing) Muirhead Tower, Edgbaston, Birmingham B15 2TT, UK 


\section{Introduction}

Ever since Riker and Ordeshook (1968) added the 'D-term' to the calculus of voting, students of voter turnout have looked towards consumption benefits to resolve 'the paradox of voter turnout' (Fiorina 1976). While 'the value of seeing democracy continue' (Downs 1957) and 'citizen duty' (Riker and Ordeshook 1968) play a key role in rational choice theories of voting (Aldrich 1993), Barry (1970) pointed out that this provides a rather unsatisfactory explanation of voter turnout. If all the hard work is done by the 'D-term' this simply shifts the question from 'why do people vote?' to 'why do people feel it is a duty to vote?' Subsequently, considerable amounts of research has focused on the normative belief that it is a civic duty to vote (Blais 2000). Moreover, because the notion of civic duty is rooted in the concept of social norms, researchers have sought to understand voter turnout from the perspective of social influence (Abrams et al. 2011; Fieldhouse and Cutts 2018; Knack 1992; Panagopoulos 2010; Rolfe 2012; Sinclair 2012). There is considerable evidence from field experiments of the importance of social pressure-or injunctive norms-in encouraging voter turnout (Gerber et al. 2008; Panagopoulos et al. 2014; Sinclair 2012). However, with a small number of exceptions (Blais et al. 2019; Fieldhouse and Cutts 2020; Glynn et al. 2009), survey research on voter turnout has tended to overlook injunctive norms. In particular, there is very little research on who applies normative pressures; whether this is conditional on shared political interests; and how social pressure affects civic duty and voter turnout.

In this paper we use political discussion network data to examine the role of injunctive norms in determining both civic duty and voter turnout and, for the first time, show how both the prevalence and power of injunctive norms of voting vary across citizens who have shared or opposing partisan identities. By separating the role of social pressure from that of normative beliefs we also demonstrate that injunctive norms affect voter turnout both directly and indirectly via civic duty. In doing so, we make two important contributions to the study of voter turnout: first, we show how partisanship shapes social norms of voting; and second we contribute towards understanding the contested role of duty in explaining turnout.

\section{Theory}

Because the chance of any individual vote determining the outcome of an election is vanishingly small, to resolve the paradox of voting (Riker and Ordeshook 1968), it is necessary to include consumption benefits of voting (those that are not dependent on the probability of affecting the outcome). This is usually referred to as the 'D-term' which, according to Riker and Ordeshook (1968, p. 28) has a number of different components, the most important being the satisfaction from complying with the ethic of voting (or duty) and affirming allegiance to a partisan 
Normative expectations affect the probability of turning out to vote.
Though part of this effect is direct, part is indirect and mediated by civic duty.
Dyadic partisanship then moderates the downstream influence of these effects.
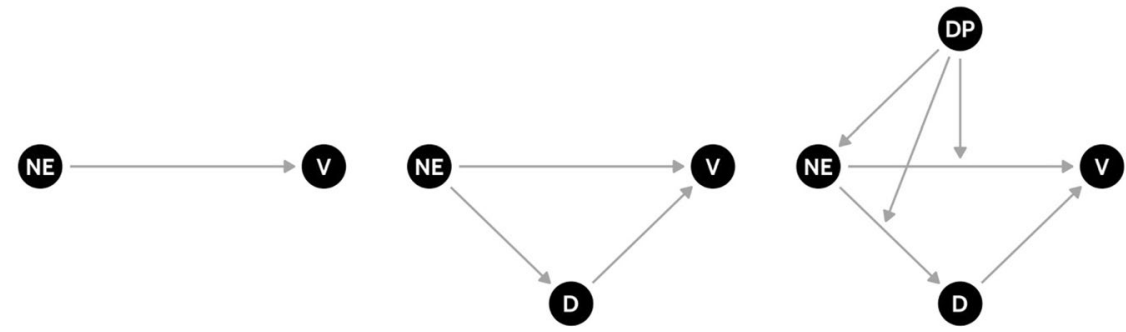

Fig. 1 The relationship between normative expectations (NE), civic duty (D), dyadic partisanship (DP), and vote $(\mathrm{V})$

preference (expressive voting). However, the reliance on civic duty as an explanation for voter turnout begs the question "why do people believe it is their duty to vote?' (Barry 1970). Putting aside whether there is a strong normative case for the existence of a duty to vote (Lomasky and Brennan 2000), the most popular and persuasive answers to this are that (a) the outcome of the an election has important consequences for a very large number of people; and (b) if everybody failed to vote the legitimacy of the democratic system would be damaged. Both of these arguments require that a demand for a social norm of voting arises due to the perceived benefits to society of widespread electoral participation. Moreover, for a social norm to be effective, social pressures (or sanctions) must develop to encourage compliance with the norm (Coleman 1990). Despite the popularity of this argument, while there is plenty of evidence linking civic duty and turnout (Blais 2000), the role of social pressure in generating a sense of duty to vote is under-researched.

To understand the relationship between social pressure, the duty to vote and voter turnout, it is necessary to differentiate between duty as a personal normative belief and duty as a social norm (Bicchieri 2017). If voting is a social norm then, for some citizens at least, the probability of voting must be conditional on normative expectations-or social approval/disapproval (Fig. 1, left panel). Consistent with this, previous research has shown that individuals vote if their informal networks attach sufficient importance to voting (e.g. Abrams et al. 2011). However, insofar as voting is a personal normative belief, then voting need not be conditional on the approval of others, but should reflect a belief that it is a moral or ethical duty to vote. Nevertheless, the personal normative belief itself may be partly the result of social pressure (Fig. 1, middle panel). Moral and ethical beliefs are ultimately the product of social learning and may therefore represent internalised social norms (Coleman 1990; Sinclair 2012). The threat of external sanctioning (i.e. social approval or disapproval) may be a pre-requisite of the development of normative beliefs about voting, such as civic duty. In other words, duty may act as a mediator between normative expectations and voter turnout. Moreover, where civic duty is a more important predictor of turnout, by extension, the direct effect of injunctive norms (net of duty) will be 
reduced. As Bicchieri (2017) points out, "even if we do not care much about a norm, strong normative expectations...will induce us to comply. Conversely, the more we value a norm, the less we worry about how many people follow it or how keenly they monitor our actions" (p. 75).

The middle panel of Fig. 1 allows for the possibility that the entire effect of social pressure is mediated by civic duty: that is, social approval or disapproval matters only insofar as it invokes a sense of duty to vote. However, there is strong evidence from field experiments that the importance of social influence on voting is not wholly attributable to civic duty. For example, Gerber et al (2008) demonstrate the role of social pressure by showing that when a subject believes that their turnout behaviour may be revealed their probability of voting increases. Moreover, this increase is much greater than the equivalent effect for subjects who receive a simple civic duty message. As Knack (1992, p. 138) argues the effect of social sanctions are not reliant on duty: "someone with a low sense of civic obligation may nonetheless vote to avoid displeasing a friend or relative". In a survey context, Fieldhouse and Cutts (2020) show that the effect of injunctive norms persist even when allowing for personal civic duty. This suggests that the relationship between injunctive norms, duty and voter turnout may be only partially mediated by civic duty.

We now turn to the role of partisanship (right hand panel Fig. 1). Citizens who vote out of duty may wish to avoid social disapproval and express their support for the democratic process, affirming their identity as a responsible citizen. This requires that there must be a willingness of citizens to apply social pressure to vote for the sake of democracy (Coleman 1990), and some argue that "there would be no social pressure in the absence of a public norm that the good citizen has a duty to vote" (Blais and Daoust 2020, p. 45). However, as indicated above, there may also be expressive (political) motivations to encourage turnout in one's social network that are not reliant on engendering a general sense of duty. According to expressive theories of voting, social pressure to vote arises not from a general sense of duty to the democratic system, but from the desire to express one's allegiance to a particular candidate or political cause (Brennan and Lomasky 1997; Jones and Hudson 2000; Schuessler 2000). In other words, if a citizen votes out of civic duty it matters not whom she votes for, what is important is simply that she votes. Voting as an expression of political or social identity, on the other hand, is concerned with how the citizen votes (Brennan and Hamlin 1998; Huddy 2001). Ultimately, expressive voting equates to "the utility or disutility of satisfying or violating one's party allegiance” (Fiorina 1976:395). While there may be no compelling normative basis for a duty to vote, the expressive reason provides the most persuasive rationale (Lomasky and Brennan 2000, p. 63).

From a rational choice perspective, Coleman (1990) argued that one might expect a conjoint norm of voting to be restricted to supporters of the same party, since votes for an opposition party or candidate would impose negative externalities. In other words, one is more likely encourage or pressure a discussant to vote if she shares a partisan preference, since increased participation of fellow partisans will lead to an increase in expected benefits. This aligns with group models of voter turnout insofar as pressure to vote arises as a result of the promise of collective goals that are achievable though high levels of group participation (Feddersen and Sandroni 2006; Schelling 1978). The perception of interdependent group interests means that those 
belonging to a particular group are more likely to face social pressures from fellow citizens or group leaders to follow a group norm of voting (Morton 1991; Uhlaner 1989). Similarly, Coate and Conlin (2004) adapted the rule-utilitarian model of voting so that only the welfare of those on the same side of an issue are considered when deciding on how to vote; and Fowler (2006) showed how shared partisanship provides a crucial element of altruistic voting (see also Fowler and Kam 2007).

Following these arguments, we hypothesise that likeminded citizens-who share support of a party - will be more likely to apply social pressure to vote. We refer to this as partisan pressure. This is an important and, as yet, untested phenomenon. Moreover, not only might we expect social norms to be applied unevenly it is possible that such pressure will be received differently if it comes from a fellow partisan compared to an opposing partisan. The proposition that the injunctive norms of voting will be more powerful for those sharing a party identification is consistent with social identity theory (SIT) (Tajfel and Turner 1979) and expressive partisanship (Huddy et al. 2015). As applied to partisanship, SIT implies that party identification is analogous to other forms of social identity (e.g. class, race or ethnicity) or supporting a sports team (Green et al. 2002; Huddy 2001). Through process of metacontrast group membership (partisanship) can lead to greater differentiation between one's own party and its opponents (Duck et al. 1995; Greene 2004). Following the logic of SIT and self-categorization, Terry and Hogg (1996) argue that normative influences have an effect beyond attitudinal effects when a subject identifies with a group. Thus, we might expect that social approval of voting will have greater influence when citizens and discussants share a party identity. Similarly, in expressive theories of voting, electoral participation is regarded as an expression of identification with a party or candidate and the expressive benefits of voting are greater when networks share a party identity (Schuessler 2000).

Given that people are more likely to mix with discussants of the same political persuasion (Huckfeldt and Sprague 1995), in most instances social pressures will serve to increase rather than reduce voting. However, in cases where political discussants support an opposing party or candidate the normative pressure to vote may be weaker, absent altogether or even negative. On the face if it such a finding would be consistent with the argument that cross-pressures reduce electoral participation (Berelson et al. 1954; Mutz 2006). However, some research has found that disagreement within close relationships can stimulate political discussion (Bello and Rolfe 2014), whilst others have demonstrated that the impact of agreement and disagreement in social networks depends not only on agreement within a dyad but on the broader political composition of the network (Huckfeldt et al. 2004; Klofstad et al. 2013; Nir 2011). While our research is relevant to this debate, it is important to note that we are primarily concerned here with dyadic influence rather than network composition. We are specifically interested in whether fellow partisans are more likely to apply normative pressures than opposing party supporters, and whether those (inter-personal) pressures are more influential than those from supporters of opposing parties Consistent with this previous research from the U.K. and the U.S. has shown that households and couples with shared partisan identification tend to have higher levels of turnout (Fieldhouse and Cutts 2018; Hersh and Ghitza 2018).

The right-hand panel in Fig. 1 reflects our novel argument that dyadic partisanship (whether or not any two political discussants share a party preference or 
identity) plays a key role in the relationship between social pressure, civic duty and turnout. To summarize, the arguments presented above suggest three ways this may occur. First, sharing a partisanship may be a precondition for applying social pressure. Indeed, one might expect that that in cases where political interests are opposing, social pressure to vote would be absent (although opposing partisanship does not preclude a shared norm of voting for the sake of contributing to the health of democracy). Second, we might expect that dyadic partisanship moderates the relationship between social pressure and voting: that is, people may be more inclined to take heed of social pressure from a discussant with whom they share a political identity. Third, the belief in the duty to vote may be more strongly shaped by discussants who share a political identity than those who do not. These propositions are formalised as the following hypotheses:

Hypotheses:

1. Citizens will be more likely to perceive that a discussant cares whether he or she votes if they share a party identification.

2. Citizens with discussants who approve of voting will be more likely to believe that voting is a civic duty.

3. Civic duty will be more closely related to the approval or disapproval of discussants who share partisanship than to discussants who have opposing party identification.

4. Perceived approval of voting will be associated with higher levels of turnout.

5. Turnout will be more closely related to the approval or disapproval of discussants who share partisanship than those who have opposing party identification.

\section{Data and Methods}

Our main data come from wave 2 of the British Election Study (BES) internet panel (Fieldhouse et al. 2017), carried out in May-June 2014, and covering the 2014 UK European Parliament elections held on Thursday 22nd May 2014. ${ }^{1}$ Although the election results received a lot of attention due to the success of UKIP, the election was unremarkable in terms of voter turnout, which was $36 \%$. While the use of internet panels for making point-estimates of voter turnout is problematic due to the over-sampling of politically engaged voters (Karp and Lühiste 2016), estimates of the covariance structure - the factors affecting turnout-tend to be less troublesome (Ansolabehere and Schaffner 2014; Berrens et al. 2003; Fieldhouse and Prosser 2017). However, because of the high proportions of reported voters in the BES internet panel it is advantageous to undertake analysis of turnout in a lower salience election because of greater variance in the dependent variable compared to high salience elections (where sampled non-voters are relatively rare) ${ }^{2}$ This specific

\footnotetext{
${ }^{1}$ Replication data is available on Dataverse at https://doi.org/10.7910/DVN/DPKQYT. Full BES datasets are available at https://www.britishelectionstudy.com/data/.

${ }^{2}$ The reported turnout for European Elections (wave 2) was 69\% using standard BES weights. All subsequent analyses are similarly weighted.
} 

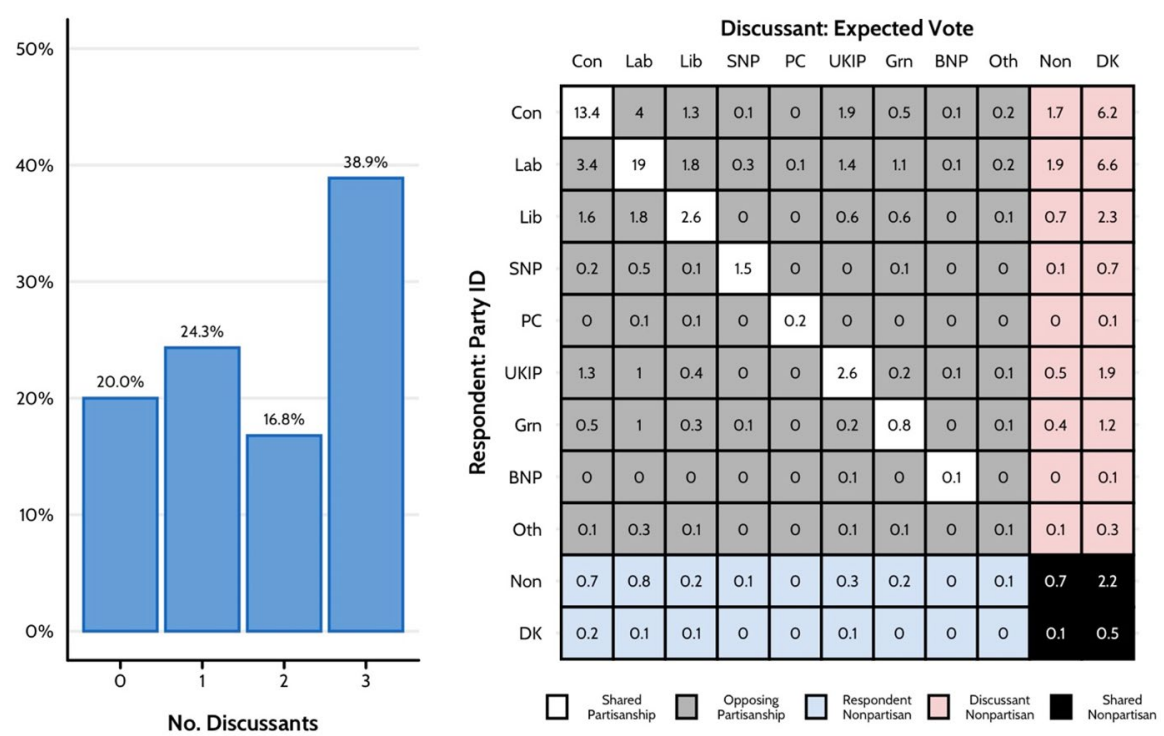

Fig. 2 Description of network data and dyadic partisanship (BES wave 2)

election was chosen because the survey included a module on political discussion networks designed to test social influences on turnout, although we also replicate our analysis using data from waves 4 and 12 of the BES when slightly more limited versions of the network module were included. ${ }^{3}$ Respondents were directed to think of up to three people that they sometimes talk to about politics (following a question about frequency of political discussion), ${ }^{4}$ and these discussants were then identified using a name generator approach. Thus, political discussants represent people most likely to be relevant to normative influence-those with whom they talk most frequently about politics, including close family and close friends. ${ }^{5}$ All 30,241 BES wave 2 respondents received this module, 24,916 (80\%) of whom named at least one

\footnotetext{
3 The network module was asked to a random subset of respondents in wave 4 about the forthcoming General Election on May 7th $2015(\mathrm{~N}=5,26)$. For 403 of these we have validated turnout information. Wave 12 asked about the local and mayoral elections which took place on May 4th 2017. Only selected areas held local or mayoral elections reducing the wave 12 sample from $\mathrm{N}=8559$ to $\mathrm{N}=3775$. Waves 4 and 12 did not include information on discussants social class and wave 12 also did not include information on the number of days politics was discussed with each discussion. Additionally data for waves 4 and 12 are affected by panel attrition and item non-response (see Online Appendix Table A1 and footnote 6).

4 The wording of the question is as follows: 'Can you think of anyone you sometimes talk to about politics? These people might or might not be relatives. *Provide up to three names starting from the top box. For example, if you only to talk to one person please fill in the top box, if you talk to two people please fill in the top two boxes, if you do not talk to anybody please skip the question.* (If you prefer, you can provide a nickname or initials).'

$553 \%$ of discussants in our sample were family, including $26 \%$ who were spouses. $29 \%$ were friends, with only $17 \%$ neighbours, co-workers or other relationships.
} 
political discussant. Of these, nearly four in ten named the maximum three discussants (see Fig. 2). To measure injunctive norms (social pressure to vote) respondents were asked of each discussant, "Do you think this person cares whether or not you voted in the European Elections?" Overall $43 \%$ of discussants were believed to care whether or not the respondent voted. ${ }^{6}$

To measure dyadic partisanship the standard British Election Study measure of party identification of the respondent ${ }^{7}$ is used in conjunction with the respondent's perception of which party their discussants usually vote for. ${ }^{8}$ The respondent's party identification is preferred to vote choice because (as discussed above), according to social identity theory, identification with a group is likely to enhance the impact of normative influence. Even in a British context where party identification is strongly correlated with current vote choice there is strong evidence that it is a meaningful concept (Huddy et al. 2018) and shows similar levels of stability to party identification in the U.S. (Schickler and Green 1997). Moreover, because of the high correlation with vote choice, by using party identification we are unlikely to lose any insight into the importance of shared preferences. For the discussant, usual vote provides a suitable equivalent, given that it is not possible to know whether another person "feels closer to a party", but it is reasonable to expect that respondents might have a good idea who a discussant usually votes for. In any case, what is important to our hypotheses is not the actual preference or identification of the discussant but the respondent's perception of that. The cross-classification of these two measures is used to classify dyadic partisanship as illustrated in the right-hand panel of Fig. 2. Overall, $41 \%$ of dyads are classed as shared partisans, $26 \%$ as opposing, $25 \%$ where the discussant doesn't have a (known) usual party, and less than 5\% where the respondent or both respondent and discussant have no party identification. ${ }^{9}$ While the numerically largest group is shared partisans, dyadic agreement is by no means dominant. Of respondents who themselves have a party identification $43 \%$ have at least one discussant of an opposing party in their immediate political discussant networks (see also Bello and Rolfe 2014). ${ }^{10}$

\footnotetext{
6 See Online Appendix Fig. 2a for equivalent figures for waves 4 and 12. The main difference is that in waves 4 and 12 respondents were more likely to identify zero discussants are therefore effectively missing from the analysis. This may be because some panellists may have actively avoided naming discussants in later waves as they would be aware that it would increase the time required to complete the questionnaire. The level and impact of item nonresponse in waves 4 and 12 is discussed in Online Appendix Table A1.

7 In the BES, party identification is measured using up to three questions. Q1. 'Generally speaking, do you think of yourself as Labour, Conservative, Liberal Democrat, (Scottish National/Plaid Cymru) [in Scotland/Wales] or what?' Q2.[Q2 if “none” at Q1] 'Do you generally think of yourself as a little closer to one of the parties than the others?' Q3. 'Which party is that?'.

8 "Which political party do you think each of these people usually votes for?".

9 The equivalent figures in wave 4 were $43.5 \%$ are shared partisans, $26 \%$ are opposing, $27.2 \%$ where the discussant doesn't have a known party, and $7.4 \%$ where the respondent or both respondent and discussant have no party ID. In wave $12,41.7 \%$ are shared partisans, $25.9 \%$ are opposing, $26.0 \%$ where the discussant doesn't have a known party, and $14.3 \%$ where the respondent or both respondent and discussant have no party ID. See Figure appendix 2a for details.

${ }^{10} 61 \%$ of respondents with a party identification have at least one shared partisan, including $21 \%$ who have both opposing and shared. $18 \%$ have no discussants with a party identification.
} 


\section{Modelling Strategy}

For the first hypothesis, we examine the extent to which respondents perceive some types of discussant to be more to likely to approve of voting, and specifically whether those sharing a partisanship are more likely to apply social pressure. The dyadic nature of our data gives it a hierarchical structure that we can exploit. We test our first hypothesis with a multilevel logistic regression model using a onewith-many dyadic design (Kenny et al. 2006), where 1 to 3 discussants (level 1) are nested within each respondent (level 2).

To test our remaining hypotheses, we take a different approach. As the dependent variables in question (civic duty and turnout) are respondent-level variables, we cannot use a one-with-many dyadic design. Instead we leverage a different type of clustering to test if pressure from some types of discussant-including fellow partisans-has more effect on the respondent's duty and turnout than social pressure from other types of discussant. Rather than nesting discussants (level 1) within respondents (level 2), we instead nest respondents (level 1) within classes of dyadic partisanship (level 2). Further, as each respondent may be a member of between 1 and 3 discussant-relationships, we use a multilevel multi-membership model (Browne et al. 2001) to analyse our data. These are similar to conventional multilevel models, but rather than allowing first-level units to be nested in only one second-level unit, multi-membership models allow them to be nested in more than one second-level unit (i.e. respondents can belong to multiple dyadic partisanship types). As these models can be difficult to fit using frequentist approaches, and can lead to convergence problems, we take a Bayesian approach instead. ${ }^{11}$

It is reasonable to expect that the frequency of political discussion between each discussant and the respondent, and thus their relative influence on the respondent, will differ from one respondent-discussant dyad to the next. To allow for this we weight each discussant's effect using the number of days that the pair discussed politics in the past week. ${ }^{12}$ To this end, we give discussants with whom the respondent has discussed politics on seven days a weight of 1 , those with whom the respondent has not discussed politics a weight of 0 , and those with whom the discussant has discussed politics between one and six days a proportionate weight between 0 and 1 . This is in addition to the standard BES weights applied to each respondent in all of our analyses.

\footnotetext{
${ }^{11}$ In particular, we fit our models using brms 2.9.2 in $\mathrm{R}$ 3.6.0. The brms package provides convenient syntax and helper functions for fitting Bayesian models using the Stan probabilistic programming language. Stan, in turn, fits models using the Hamiltonian Monte Carlo algorithm. All models were fit using Stan 2.18.1 and mixed well and each estimates' $\widehat{R}$ statistic indicated convergence.

12 This was not possible for wave 12 because the amount of discussion question was not asked. Thus, in wave 12 all respondents are weighted equally.
} 


\section{Dyadic Party Identification}

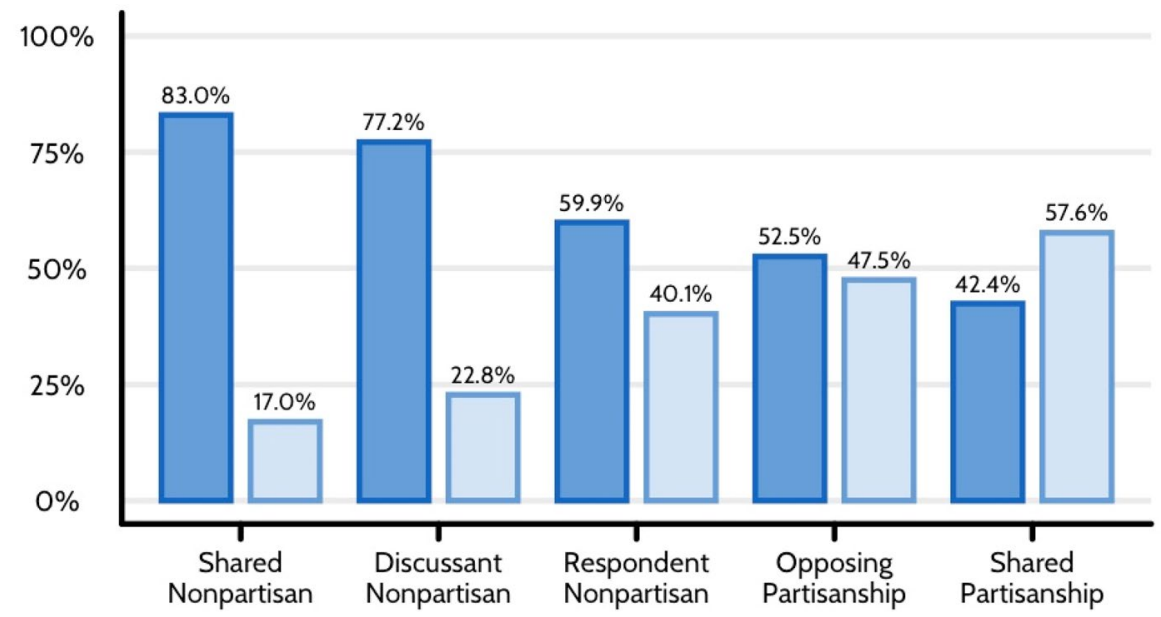

Do not approve $\square$ Approve

Fig. 3 Bivariate relationship between approval and dyadic partisanship (BES wave 2)

\section{Results}

\section{Injunctive Norms and Shared Partisanship}

Figure 3 shows the bivariate relationship between dyadic partisanship and approval of voting. As hypothesised, approval is highest among dyads sharing a partisanship (58\%). This is notably higher than the equivalent proportion among opposing partisans $(47 \%)$, suggesting prima facia evidence for hypothesis $1 .{ }^{13}$ Unsurprisingly, in cases where the discussant is not perceived to have a party identification perceived approval of voting is much lower. However, these differences are likely to be due in part to differences in the characteristics of respondents and discussants between dyadic partisanship types. We therefore now consider the multivariate models referred to above.

To test the first hypothesis, we model discussant approval as a function of both discussant and respondent characteristics. As noted above, we use a multilevel logistic regression model where discussants (level 1) are nested within respondents (level 2). Given that approval is a discussant-level variable, it is appropriate to focus on discussant-level characteristics. The key discussant-level explanatory

\footnotetext{
13 See Online Appendix Table A2 and Fig. 3a for equivalent figures for waves 4 and 12 where a very similar pattern is seen, although caring about voting is higher at the high salience general election (wave 4). 


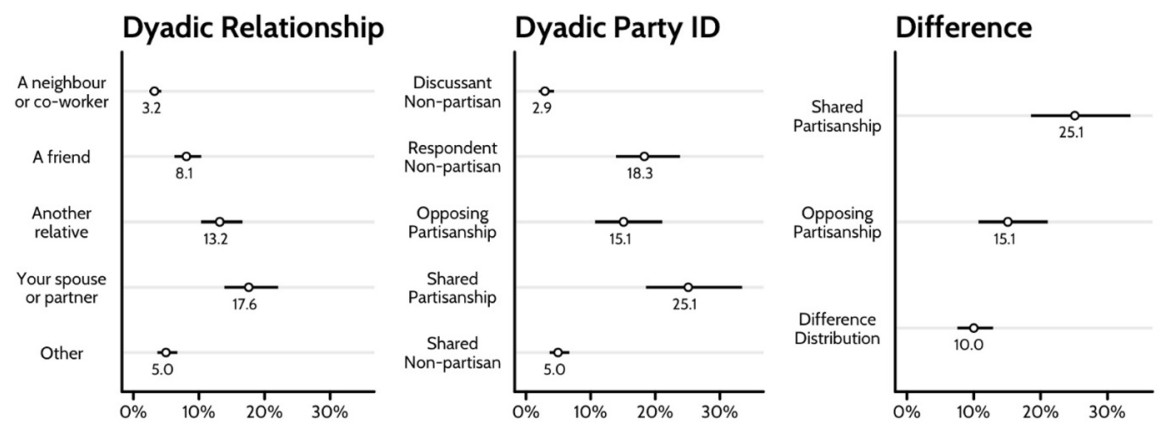

Fig. 4 Predicted probabilities of approval for dyadic relationship types and dyadic partisanship types during the 2014 European elections with $95 \%$ credible intervals (BES wave 2)

variable is dyadic partisanship. We control for the social class of the discussant, and the frequency of dyadic political discussion because we might expect that respondents would be more likely to pick up messages about approval and disapproval the more often they discuss politics together. We also include controls for dyadic social relationship as it has previously been shown that social pressures from close family members tend to be most influential (Blais et al. 2019; Fieldhouse and Cutts 2020). This finding is repeated in our data as shown in Fig. 4, confirming the importance of this as a control variable.

While we test our first hypothesis at the discussant-level, there may be variation in perceived approval according to characteristics of the respondent. We therefore control for respondent-level variables, including age, gender, education, whether or not the respondent is married/cohabiting, their attention to politics, the total number of discussants that they provided, and the strength of their party identification. The latter serves an important role in that it protects against conflating the effect of possible stronger partisanship amongst respondents in dyads where both individuals have a party identification. The multivariate model of approval is shown in the Online Appendix Table A3.

The effect of our respondent-level variables is as expected. Strong identifiers, older people, and the more educated are more likely to perceive approval of voting from their discussants. Despite these variables having large effects, as anticipated, discussant-level variables appear to matter more. Figure 4 gives predicted probabilities for both dyadic relationship and dyadic partisanship. ${ }^{14}$ As hypothesised, respondents perceive discussants with whom they share a party identification to be more likely to care whether they voted than where the discussant is a non-partisan. This is also true of opposing partisan identifiers, albeit to a lesser extent. That is, the coefficients for both opposing and shared identification are different to the reference

\footnotetext{
${ }^{14}$ In all predictions continuous/ordinal variables are set at their mean, gender as male, and marital status as not married/cohabiting. See Appendix Fig. 4a for equivalent figures for wave 4 and 12 which show a very similar pattern.
} 
category, but comparing their respective effect sizes and credible intervals, the latter are more likely to be perceived to approve of the respondent voting than the former. The effects are as large, or larger than, the equivalent effects for social relationship, which appear to be a function of social distance (Blais et al. 2019; Fieldhouse and Cutts 2020). Spouses and partners have a greater effect on respondents' perceptions of discussant approval of voting than other family members, which in turn matter more than friends do and so on. Overall, the model provides support for our first hypothesis.

\section{Injunctive Norms, Shared Partisanship and Civic Duty}

We have shown that shared partisanship is associated with a greater incidence of injunctive norms within respondent-discussant dyads. Respondents are more likely to perceive that the discussant cares whether she votes if she shares the same party identification. The remaining questions concern the impact of these norms on civic duty and turnout, and whether respondents sharing partisanship with a discussant are more responsive to the approval or disapproval of that discussant (i.e. is the effect of discussant approval greater for shared partisans than opposing partisans?).

As noted above we test our second and third hypotheses using a multi-membership logistic regression model of respondent civic duty. This model nests respondents within dyadic partisanship and includes random slopes for approval to allow its effect to vary across different dyads. As before, we include controls for other factors that might influence our outcome variable, in this case civic duty (Blais and Daoust 2020; Bowler and Donovan 2013), though they are also selected to be relevant in the turnout models (Smets and Van Ham 2013). They include respondents' age, gender, education, if they are cohabiting, how often they discuss politics, how much attention they pay to politics, and measures of internal and external political efficacy. We also include the fixed effect of discussant approval which estimates the effect of discussant approval in general, i.e. regardless of dyadic partisanship or dyadic relationship.

The results of the duty model are shown in Online Appendix Table A4. The effects of the control variables are broadly similar to what we expect to find: higher levels of civic duty are associated with being female, having more education, political attention, and the respondent's own party identification. More importantly the mean impact of approval on duty across all types of dyadic partisanship is strong and positive, providing support for our second hypothesis. However, the fixed and random effects of approval moderated by dyadic partisanship are difficult to interpret. Not only are the coefficients on the log-odds scale, but to infer the impact of discussant approval and dyadic partisanship it is necessary to take into account the overall intercept, the fixed effect of discussant approval, the random intercepts of dyadic partisanship, the random slopes for discussant approval moderated by dyadic partisanship, and their collective variation. To ease interpretation, we plot the predicted probabilities for each dyadic partisanship type where the discussant does and does not care whether the respondent voted, as well as the difference between these probabilities (Fig. 5, left and right panels respectively). We see that approval 


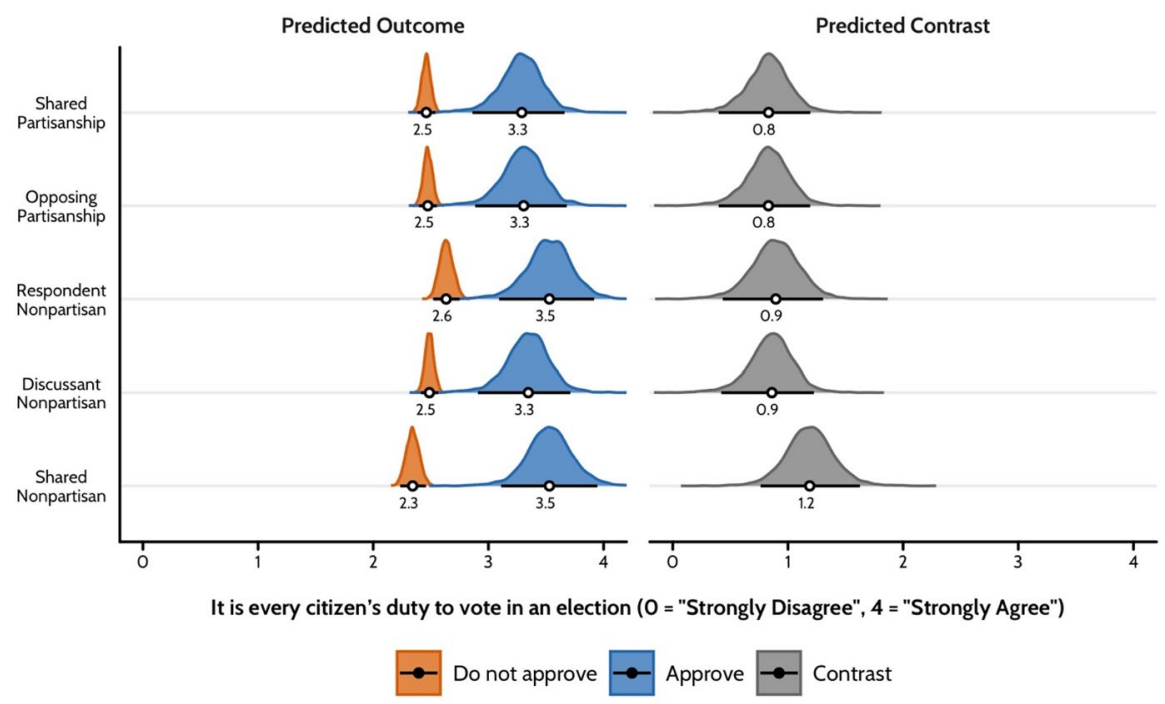

Fig. 5 Effect of approval on civic duty by dyadic partisanship (BES wave 2)

of discussants has a large positive and fairly uniform effect on the civic duty of the respondent across all classes of dyadic partisanship. The greatest difference in duty between approving and non-approving dyads is among shared non-partisans, although the credible intervals of the estimates are large and the estimate of difference (the right-hand panel) overlaps with that of other dyadic partisanship types. In other words, while we find support for the second hypothesis that civic duty is influenced by injunctive norms, we find no support for the third hypothesis that civic duty is more sensitive to the approval or disapproval of discussants who share partisanship. These results are replicated in waves 4 and 12 (see Online Appendix Fig. 5a).

\section{Injunctive Norms, Shared Partisanship and Voter Turnout}

So far we have established that approval of voting is more widespread in shared partisan dyads and that civic duty is higher where there is social approval of voting. The question we now turn to is whether that approval matters for voter turnout and whether the injunctive norms of voting are more influential when coming from shared partisans. The full details of the multi-membership model of turnout are provided in Online Appendix Table A5. As noted above, the control variables are the same as those used in the model of duty. The effect of the control variables on turnout are as expected and require no further discussion. As previously, to best illustrate the key evidence we rely not on the table of coefficients but on the predicted probabilities and contrasts (Fig. 6).

Figure 6 shows that predicted turnout is higher where injunctive norms are present regardless of dyadic partisanship. When social pressure is absent there a substantial difference between dyadic partisanship types and, in dyads where both 


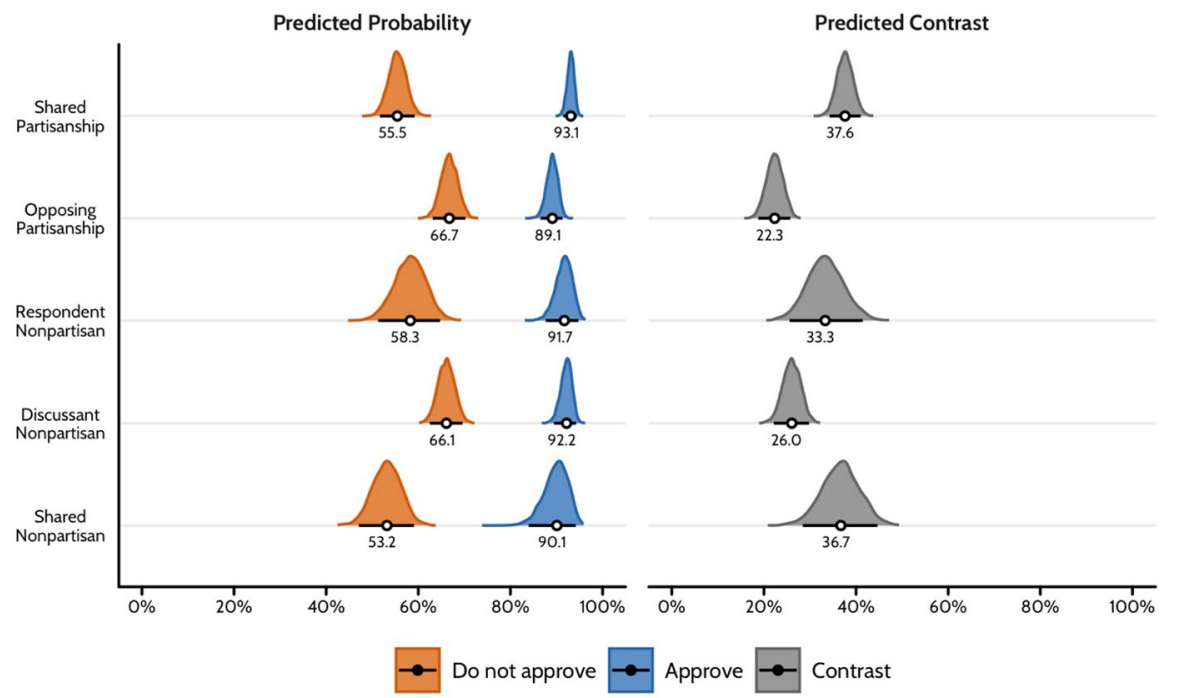

Fig. 6 Predicted turnout probabilities and contrasts by dyadic partisanship (BES wave 2)

discussants are partisan, turnout is higher in opposing partisan than shared partisan dyads. However, when social pressure is present the pattern reverses and the highest probability of voting is in shared partisan dyads. Indeed, the contrast plotswhich show the difference between the predicted value for dyads with and without approval-indicate that the largest effect of approval of voting is among shared partisan dyads, closely followed by those in which the respondent is non-partisan but the discussant has a party identification.

The most useful comparison is between shared and opposing partisans, as these dyads are most similar insofar as both discussants in each identify with a party. As these estimates come from Bayesian models that estimate the entire posterior probability distribution, we can calculate the difference in the difference between shared partisan dyads and opposing partisan dyads quite easily. In this case, the differencein-difference is 0.15 (with a $95 \%$ credible interval of 0.11 to 0.20 ). In other words, approval has a 15 percentage-point larger positive effect on turnout in shared partisan dyads than in opposing partisan dyads. This comparison supports hypothesis 4: that turnout is more closely related to the approval or disapproval of discussants who share a partisanship than that of opposing partisans. However, these results are not replicated in the smaller samples collected in wave 4 and wave 12 of the BES (see Online Appendix Fig. 6a). Wave 4, which relates to the 2015 General Election, shows high levels of turnout, especially in dyads with approval of voting leading to ceiling effects on differences. We do see some evidence of a slightly larger differential for shared partisans in the validated vote sample but the estimates are subject to a large amount of uncertainty due to the small sample $(\mathrm{N}=397)$. Wave 12 , which relates to the local elections of 2017 , does not have the same problem with ceiling effects but displays little variation in the effect of approval across the different categories of dyadic partisanship (Online Appendix Fig. 6a(iii)). One possible 


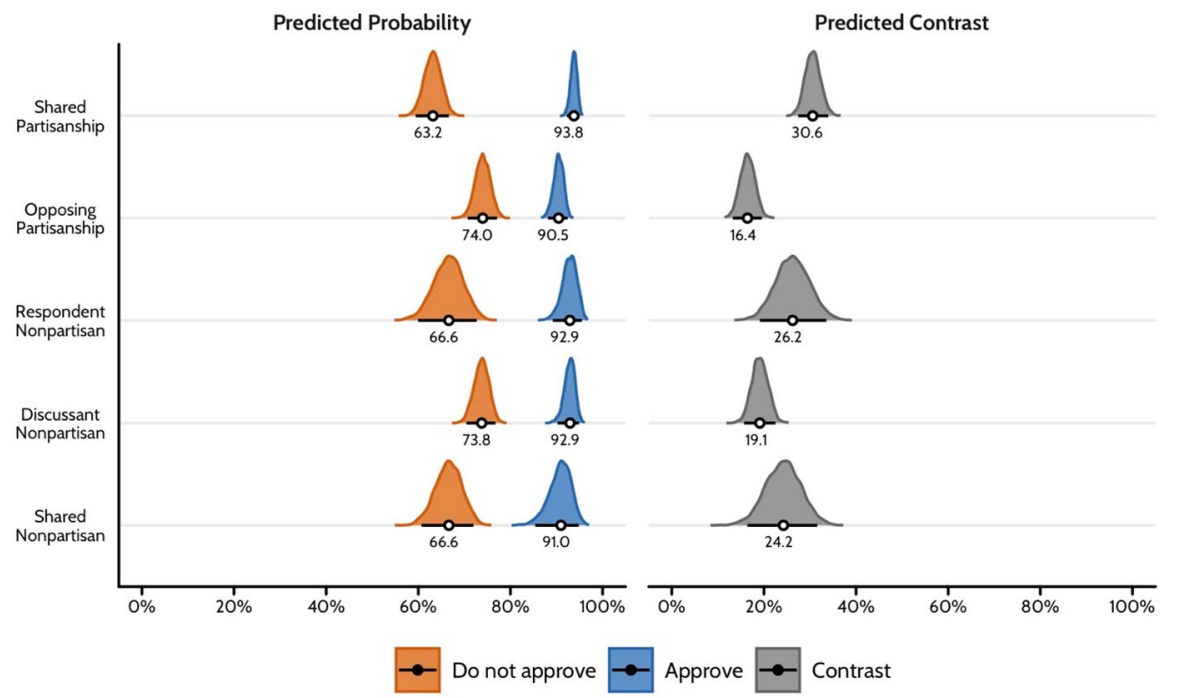

Fig. 7 Predicted turnout probabilities and contrasts by dyadic partisanship, controlling for civic duty (BES wave 2)

explanation for this difference is the electoral context: the 2014 European Parliament Elections (wave 2) in the UK were fought largely around the issue of Britain's European Union membership. A large Eurosceptic protest vote enabled UKIP to win the largest share of the vote, meaning that many supporters of the traditional larger parties (especially the Conservatives) voted against their usual party. In wave 12 the questions related to the local elections in which the distribution of party support was closer to 'normal' patterns, with the Conservatives and Labour as the largest parties. Until we can conduct further research, we should assume that the differential effect sizes of approval found in wave 2 may be a reflection of the specific electoral context in 2014, and/or the lack of differences in wave 4 and 12 result from problems with the data in those waves, including lack of variance in turnout, panel attrition and item non-response.

We argued above that the effect of dyadic social pressure on voter turnout may be partly transmitted by a change in the level of civic duty. We have already shown that agreement with the norm of civic duty tends to be greater when discussants care whether the respondent votes or not. Although this effect was found to be equally strong for opposing and shared party identifiers, because approval itself is not found equally across types of dyadic partisanship (as shown in Fig. 4), the mediated effect on turnout is not equal for shared identifiers and opposing identifiers. This also means that the direct effect of approval on turnout-and how that varies by dyadic partisanship - may be smaller than initially estimated once we allow for its indirect effect via civic duty. To investigate this, we add civic duty as a control variable in the model of turnout. The full results of this model are shown in Online Appendix Table A6 but, as previously, the results are best illustrated by showing the predicted probabilities by dyadic partisanship and their contrast (Fig. 7). We see that 
even when allowing for the effect of civic duty, approval has a large direct effect on turnout across all dyadic partisanship types, a result which is replicated in waves 4 and 12 (see Online Appendix Fig. 7a). However, as in the previous model, while in wave 2 we find that the largest effect of approval is among shared partisans and the smallest effect among opposing identifiers, the differential effect of approval is not replicated in waves 4 and 12 .

\section{Discussion}

Existing research suggests that it is difficult to explain why people vote without invoking the concept of social norms. However, due in part to the limited availability of relational data, political scientists have tended to focus on personal normative beliefs, especially civic duty, ignoring the role of normative influence, either directly on voting or indirectly via civic duty. This has made it difficult to understand the process of normative influence, including who is most likely to apply normative pressure, and whether or not some political discussion partners are more influential than others. In this article we have presented a number of new and important findings concerning the relationships between injunctive norms, civic duty and turnout and how these relationships are shaped by party identification. For the first time we have demonstrated the role of shared partisan identification in determining the extent of social pressure to vote. We found strong evidence for partisan pressurethat is that norms are selectively enforced (Hypothesis 1). In short, people are more likely to perceive that their fellow partisans care whether they vote than discussants who do not share a party affiliation, especially identifiers of opposing parties. Second, we demonstrated that this social pressure is associated with higher levels of civic duty (Hypothesis 2), which in turn is correlated with voter turnout. Although the size of the effect of social pressure on duty (the coefficient) was not found to vary by dyadic partisanship (Hypothesis 3), because the amount of social pressure is higher in shared partisan dyads, the level of duty also tends to be higher. Moreover, despite the importance of social pressure in shaping civic duty, approval of voting was found to be strongly associated with turnout even after allowing for civic duty (Hypothesis 4). However, we do not find consistent evidence that social pressure from fellow partisans was more strongly related to turnout than that from opposing partisans (Hypothesis 5). The failure to consistently identify the differential effect may reflect either the unique electoral context of our primary dataset (2014), peculiarities of the supplementary samples (2015 and 2017), or both.

It is important to remember that these findings relate to interpersonal influence through dyadic injunctive norms and partisanship, not to the character of whole networks (Huckfeldt et al. 2004; Nir 2011). While we find that shared partisanship stimulates social pressure to vote, it is entirely plausible that disagreement could simultaneously stimulate turnout through increased partisan discussion (Foos and de Rooij 2016). The latter, as Foos and de Rooij point out, may reflect friendly competition ('I will vote to offset your vote') whilst the former relies on a desire for cooperation ('you should vote because our party needs your support'). 
Before accepting these conclusions, we should consider possible problems of endogeneity that threaten causal inference. First, regarding the effect of shared partisanship on approval, it might be argued that there is reciprocal causality. This would require that respondents select discussants that care about their turnout behaviour and, in turn, this would make them more likely to adopt a shared a party preference. In other words, the showing of approval of turnout by a discussant would have to influence the party identification of the respondent. This seems rather unlikely. Certain types of discussant may well be both more likely to approve and likely to influence the party preference of respondent, but this must be attributable to some characteristics of the dyad (e.g. the closeness of the relationship) and is therefore a problem of omitted variable bias rather than reverse causality. To mitigate this, we have included a substantial range of individual and dyadic controls. It is hard to think of many other characteristics not already included in the approval model that might be related to both shared partisanship and approval of voting. However, we acknowledge there may be omitted variables that are related to both sharing partisanship and applying normative pressure which means that causal inference needs to be made with caution. Regarding the relationship between approval and turnout, similar arguments apply.

Another possible threat to inference is that civic duty and turnout of the respondent may influence the likelihood of perceiving approval amongst discussants. However, there is no theoretical or logical reason that any misperception should be restricted to those sharing the same partisanship. The fact that the inclusion of a large number of other individual and dyadic controls makes little difference to the effect of dyadic partisanship reassures us that dyadic partisanship most likely does influence perceived approval of voting. Whilst endogeneity can rarely be ruled out in observational cross-sectional analysis, it is important to note that the existence of endogeneity per se does not necessarily render analysis obsolete. By its very nature, influence via social norms and social networks is an endogenous process. People influence each other, and this is precisely our object of interest. If we are to understand these routes of influence better, then it is necessary to recognise and acknowledge this and employ relational data as we have here. Indeed, whilst experimental designs have proved very successful at identifying causal effects (e.g. Sinclair 2012) they have more limited potential for uncovering the underlying patterns of normative influence. Network designs may be inferior for making causal inference, but arguably better suited for describing the conditions under which normative pressure is applied-an important and sometimes undervalued endeavour (Blais and Daoust 2020; Hersh and Ghitza 2018). The network data used here has enabled us to come to an important conclusion: citizens are more likely to perceive normative pressure from fellow partisans.

In sum, we believe the findings of this research are important in furthering our understanding of how social norms of voting operate, and the crucial role of partisanship. This matters because models of turnout are heavily reliant on the concepts of norms and, very often, this is reduced to personal normative beliefs, especially civic duty, which is frequently treated as an exogenous characteristic of autonomous and isolated citizens. We suggest that this is unsatisfactory: norms are social constructs and, if normative beliefs of voting are critical to 
understanding turnout, then we must at least attempt to understand more about where they come from and when they are most effective. Here we have taken a small step in that direction, making a clear link between party identity and normative influence on both civic duty and voter turnout.

Acknowledgement This research was supported by the Economic and Social Research Council, British Election Study Awards ES/K005294/1 and ES/S015671/1.

Open Access This article is licensed under a Creative Commons Attribution 4.0 International License, which permits use, sharing, adaptation, distribution and reproduction in any medium or format, as long as you give appropriate credit to the original author(s) and the source, provide a link to the Creative Commons licence, and indicate if changes were made. The images or other third party material in this article are included in the article's Creative Commons licence, unless indicated otherwise in a credit line to the material. If material is not included in the article's Creative Commons licence and your intended use is not permitted by statutory regulation or exceeds the permitted use, you will need to obtain permission directly from the copyright holder. To view a copy of this licence, visit http://creativecommons.org/licen ses/by/4.0/.

\section{References}

Abrams, S., Iversen, T., \& Soskice, D. (2011). Informal social networks and rational voting. British Journal of Political Science, 41(2), 229-257.

Aldrich, J. H. (1993). Rational choice and turnout. American Journal of Political Science, 37(1), 246-278.

Ansolabehere, S., \& Schaffner, B. F. (2014). Does survey mode still matter? Findings from a 2010 multi-mode comparison. Political Analysis, 22(3), 285-303.

Barry, B. M. (1970). Sociologists, economists, and democracy. London: Sollier-Macmillan.

Bello, J., \& Rolfe, M. (2014). Is influence mightier than selection? Forging agreement in discussion networks during a campaign. Social Networks, 36, 134-146.

Berelson, B., Lazarsfeld, P. F., \& McPhee, W. N. (1954). Voting: A study of opinion formation in a presidential campaign. Chicago, London: University of Chicago Press.

Berrens, R. P., Bohara, A. K., Jenkins-Smith, H., Silva, C., \& Weimer, D. L. (2003). The advent of internet surveys for political research: A comparison of telephone and internet samples. Political Analysis, 11(1), 1-22.

Bicchieri, C. (2017). Norms in the wild: How to diagnose, measure, and change social norms. New York: Oxford University Press.

Blais, A. (2000). To vote or not to vote?: The merits and limits of rational choice theory. Pittsburgh, PA: University of Pittsburgh Press.

Blais, A., \& Daoust, J.-F. (2020). The motivation to vote: explaining electoral participation. Vancouver: UBC Press.

Blais, A., Galais, C., \& Coulombe, M. (2019). The effect of social pressure from family and friends on turnout. Journal of Social and Personal Relationships, 36(9), 2824-2841.

Bowler, S., \& Donovan, T. (2013). civic duty and turnout in the UK Referendum on AV: What shapes the duty to vote? Electoral Studies, 32(2), 265-273.

Brennan, G., \& Hamlin, A. (1998). Expressive voting and electoral equilibrium. Public Choice, 95, 149-175.

Brennan, G., \& Lomasky, L. E. (1997). Democracy and decision: The pure theory of electoral preference. Cambridge: Cambridge University Press.

Browne, W. J., Goldstein, H., \& Rasbash, J. (2001). Multiple membership multiple classification (MMMC) models. Statistical Modelling: An International Journal, 1(2), 103-124.

Coate, S., \& Conlin, M. (2004). A group rule-utilitarian approach to voter turnout: Theory and evidence. American Economic Review, 94(5), 1476-1504. 
Coleman, J. S. (1990). Foundations of social theory. Cambridge, MA, London: Belknap Press of Harvard University Press.

Downs, A. (1957). An economic theory of democracy. New York, NY: Harper.

Duck, J. M., Hogg, M. A., \& Terry, D. J. (1995). Me, us and them: Political identification and the third-person effect in the 1993 Australian Federal Election. European Journal of Social Psychology, 25(2), 195-215.

Feddersen, T. J., \& Sandroni, A. (2006). A theory of participation in elections. American Economic Review, 96(4), 1271-1282.

Fieldhouse, E., \& Cutts, D. (2018). Shared partisanship, household norms and turnout: Testing a relational theory of electoral participation. British Journal of Political Science, 48(3), 807-823.

Fieldhouse, E., \& Cutts, D. (2020). Do as I say or do as I do? How social relationships shape the impact of descriptive and injunctive norms of voting. British Journal of Political Science. https://doi. org/10.1017/S0007123420000058.

Fieldhouse, E., Green, J., Evans, G., Schmitt, H., Van der Eijk, C., Mellon, J., \& Prosser, C. (2017). British Election Study, 2015: Internet Panel Survey. Waves. https://doi.org/10.15127/1293723.

Fieldhouse, E., \& Prosser, C. (2017). Horses for courses: Using internet surveys for researching public opinion and voting behavior. In J. Fisher, E. Fieldhouse, M. N. Franklin, R. K. Gibson, M. Cantijoch, \& C. Wlezien (Eds.), The routledge handbook of elections, voting behaviorand public opinion (pp. 472-483). Abington: Routledge.

Fiorina, M. P. (1976). Voting decision-Instrumental and expressive aspects. Journal of Politics, 38(2), $390-413$.

Foos, F., \& de Rooij, E. A. (2016). All in the family: Partisan Disagreement and electoral mobilization in intimate networks-A spillover experiment. American Journal of Political Science, 00, 1-16.

Fowler, J. H. (2006). Altruism and turnout. Journal of Politics, 68(3), 674-683.

Fowler, J. H., \& Kam, C. D. (2007). Beyond the self: Social identity, altruism, and political participation. Journal of Politics, 69(3), 813-827.

Gerber, A. S., Green, D. P., \& Larimer, C. W. (2008). Social pressure and voter turnout: Evidence from a large-scale field experiment. The American Political Science Review, 102(1), 16.

Glynn, C. J., Huge, M. E., \& Carole a. Lunney. . (2009). The influence of perceived social norms on college students' intention to vote. Political Communication, 26(1), 48-64.

Green, D. P., Palmquist, B., \& Schickler, E. (2002). Partisan hearts and minds: Political parties and the social identities of voters. New Haven, CN, London: Yale University Press.

Greene, S. (2004). Social identity theory and party identification. Social Science Quarterly, 85(1), $136-153$.

Hersh, E., \& Ghitza, Y. (2018). Mixed partisan households and electoral participation in the United States. PLoS ONE, 13(10), e0203997.

Huckfeldt, R., Johnson, P. E., \& Sprague, J. D. (2004). Political disagreement: The survival of diverse opinions within communication networks. Cambridge: Cambridge University Press.

Huckfeldt, R., \& Sprague, J. D. (1995). Citizens, politics, and social communication: Information and influence in an election campaign. Cambridge: Cambridge University Press.

Huddy, L. (2001). From social to political identity: Examination of social identity theory. Political Psychology, 22(1), 127-156.

Huddy, L., Bankert, A., \& Davies, C. (2018). Expressive versus instrumental partisanship in multiparty european systems. Political Psychology, 39, 173-199.

Huddy, L., Mason, L., \& Aarøe, L. (2015). Expressive partisanship: Campaign involvement, political emotion, and partisan identity. American Political Science Review, 109(1), 1-17.

Jones, P., \& Hudson, J. (2000). Civic duty and expressive voting: Is virtue its own reward? Kyklos, 53(1), $3-16$.

Karp, J. A., \& Lühiste, M. (2016). explaining political engagement with online panels. Public Opinion Quarterly, 80(3), 666-693.

Kenny, D. A., Kashy, D. A., \& Cook, W. L. (2006). Dyadic data analysis. New York, NY: Guilford Press.

Klofstad, C. A., Sokhey, A. E., \& McClurg, S. D. (2013). Disagreeing about disagreement: How conflict in social networks affects political behavior. American Journal of Political Science, 57(1), 120-134.

Knack, S. (1992). Civic norms, social sanctions and voting turnout. Rationality and Society, 4(2), 133.

Lomasky, L. E., \& Brennan, G. (2000). Is there a duty to vote? Social Philosophy and Policy, 17(1), 62-86.

Morton, R. B. (1991). Groups in rational turnout models. American Journal of Political Science, 35(3), 758-776. 
Mutz, D. C. (2006). Hearing the other side: Deliberative versus participatory democracy. Cambridge: Cambridge University Press.

Nir, L. (2011). Disagreement and opposition in social networks: Does disagreement discourage turnout? Political Studies, 59(3), 674-692.

Panagopoulos, C. (2010). Affect, social pressure and prosocial motivation: Field experimental evidence of the mobilizing effects of pride, shame and publicizing voting behavior. Political Behavior, 32(3), 369-386.

Panagopoulos, C., Larimer, C. W., \& Condon, M. (2014). Social pressure, descriptive norms, and voter mobilization. Political Behavior, 36(2), 451-469.

Riker, W. H., \& Ordeshook, P. C. (1968). A theory of calculus of voting. American Political Science Review, 62(1), 25-42.

Rolfe, Meredith. 2012. Voter Turnout : A Social Theory of Political Participation. New York ; Cambridge : Cambridge University Press.

Schelling, T. C. (1978). Micromotives and macrobehavior. New York: W.W. Norton.

Schickler, E., \& Green, D. P. (1997). The stability of party identification in western democraciesResults from eight panel surveys. Comparative Political Studies, 30(4), 450-483.

Schuessler, A. A. (2000). A logic of expressive choice. Princeton, London: Princeton University Press.

Sinclair, B. (2012). The social citizen: Peer networks and political behavior. Chicago: University of California Press.

Smets, K., \& Van Ham, C. (2013). The embarrassment of riches? A meta-analysis of individual-level research on voter turnout. Electoral Studies, 32(2), 344-359.

Tajfel, H., \& Turner, J. (1979). An integrative theory of intergroup conflict. In W. G. Austin \& S. Worchel (Eds.), The social psychology of intergroup relations. Monterey, CA: Brooks-Cole.

Terry, D. J., \& Hogg, M. A. (1996). Group norms and the attitude-behavior relationship: A role for group identification. Personality and Social Psychology Bulletin, 22(8), 776-793.

Uhlaner, C. J. (1989). Rational turnout: The neglected role of groups. American Journal of Political Science, 33(2), 390.

Publisher's Note Springer Nature remains neutral with regard to jurisdictional claims in published maps and institutional affiliations. 